\title{
Properties of biochar-amended soils and their sorption of imidacloprid, isoproturon, and atrazine
}

Jie Jin ${ }^{\mathrm{a}, \mathrm{c}}$, Mingjie Kang ${ }^{\mathrm{a}}$, Ke Sun ${ }^{\mathrm{a}, *}$, Zezhen Pan ${ }^{\mathrm{a}}$, Fengchang Wu $\mathrm{b}^{\mathrm{b}}$, Baoshan Xing ${ }^{\mathrm{c}}$

${ }^{a}$ State Key Laboratory of Water Simulation, School of Environment, Beijing Normal University, Beijing 100875, China

${ }^{\mathrm{b}}$ State Key Laboratory of Environmental Criteria and Risk Assessment, Chinese Research Academy of Environmental Sciences, Beijing 100012, China

${ }^{c}$ Stockbridge School of Agriculture, University of Massachusetts, Amherst, MA 01003, USA

*Corresponding authors: (86)-10-58807493 (phone), (86)-10-58807493 (fax), email: sunke@bnu.edu.cn (K. SUN); 
ABSTRACT: Biochars produced from rice straw, wheat straw and swine manure at 300,450 and $600{ }^{\circ} \mathrm{C}$ were added to soil at $1,5,10$, or $20 \%$ levels to determine whether they would predictably reduce the pore water concentration of imidacloprid, isoproturon, and atrazine. The sorption capacity of the mixtures increased with increasing biochar amounts. The enhanced sorption capacity could be attributed to the increased organic carbon (OC) content and surface area (SA) as well as the decreased hydrophobicity. Biochar dominated the overall sorption when its content was above $5 \%$. The OC contents of the mixtures with $10 \%$ and $20 \%$ biochar were generally lower than the predicted values. This implies possible interaction between soil components and biochar and/or the effect of biochar oxidation. For soils amended with biochars produced at $300{ }^{\circ} \mathrm{C}$, the $\mathrm{N}_{2} \mathrm{SA}\left(\mathrm{N}_{2}-\mathrm{SA}\right)$ values were underestimated. The predicted $\mathrm{CO}_{2} \mathrm{SA}\left(\mathrm{CO}_{2}-\mathrm{SA}\right)$ values of the mixtures at the biochar content of $10 \%$ and $20 \%$ were generally higher than the experimental values. Sorption of imidacloprid to the soils amended with biochar at $10 \%$ and $20 \%$ levels, excluding the soils amended with rice (SR300) and wheat (SW300) straw-derived biochar produced at $300{ }^{\circ} \mathrm{C}$, was lower than the predicted value. For SR300 and SW300, the intrinsic sorption capacity of biochar was enhanced by 1.3-5.6 times, depending on the biochar, solute concentration, and biochar dose. This study indicates that biochars would be helpful to stabilize the soil contaminated with imidacloprid, isoproturon, and atrazine, but the sorption capacity of the mixtures could exceed or fall short of predicted values without assuming a cross-effect between soil and biochar. 
Keywords: Biochar; Soil; Sorption; Pesticides; Herbicides, Insecticides 


\section{Introduction}

Biochar refers to carbonaceous residues of incomplete combustion of carbon-rich biomass under oxygen-limited conditions at relatively low temperatures $\left(<700{ }^{\circ} \mathrm{C}\right)$ (Lehmann and Joseph, 2009). It has attracted more and more attention as a soil amendment at levels up to $5 \%-10 \%$ by weight (about $100 \mathrm{t} / \mathrm{ha}$ ) to improve soil fertility and plant productivity and sequester carbon (Lehmann, 2007; Lehmann and Joseph, 2009; Woolf et al., 2010). Lately biochar is of interest as an effective sorbent for hydrophobic organic compounds (HOCs) in soil (Jones et al., 2011; Teixidó et al., 2013; Yang and Sheng, 2003). Related pyrogenic substances, known as environmental black carbon $(\mathrm{BC})$, are widely present in soils and sediments, in fire-impacted soils comprising up to 30-45\% of total organic carbon (OC) (Cornelissen et al., 2005). BC exhibited 10-1,000 times stronger affinity with HOCs than natural organic matter (NOM) (Cornelissen and Gustafsson, 2005; Cornelissen et al., 2005; Yang and Sheng, 2003), so even a small amount of environmentally or artificially added BC in soil and sediment should dominate the overall sorption of organic contaminants. For instance, at content of $0.1 \%$, the biochar produced from pine needle at $400{ }^{\circ} \mathrm{C}$ dominated the overall sorption of naphthalene (Chen and Yuan, 2011). Moreover, sorption in the biochar-soil mixtures was generally enhanced with increasing biochar dose compared to the soil alone (Chen and Yuan, 2011; Teixidó et al., 2013). The sorption ability of HOCs to biochar has been reported to be affected by many factors, such as heat treatment temperatures (HTTs), feedstock sources, etc (Chen et al., 2008; Sun et al., 
2012; Sun et al., 2013a). However, previous studies about biochar amendment mainly focused on the biochar produced from plant residue (Chen and Yuan, 2011; Teixidó et al., 2013). The enhancement effect of animal waste-derived biochars on soil sorption needs further study.

On the other hand, the sorption ability of biochar was known to depend strongly on its physicochemical properties, such as surface area, bulk or surface polarity, and mineral content (Chen et al., 2008; Sun et al., 2012; Sun et al., 2013a). With addition of biochar to soil, the physicochemical properties of biochar are expected to be changed, due to the possible interactions of biochar with soil components, such as abundant minerals or dissolved organic carbon (DOC). The components could block pore surfaces or compete for binding sites of biochar, making biochar surface less available for HOCs (Chen and Yuan, 2011; Cornelissen and Gustafsson, 2005). In addition, a reduction of the surface area (SA) of biochars was observed with increasing DOC contents (Garcia-Jaramillo et al., 2015). Thus, most of studies observed sorption attenuation of biochars coexisted with soil, compared to the pristine biochar (Chen and Yuan, 2011; Teixidó et al., 2013). However, a recent study found that alumina and montmorillonite exhibited a pore-expanding effect on biochar, which resulted in higher sorption of herbicides to the mineral-treated biochars than to the untreated biochars ( $\mathrm{Li}$ et al., 2015). The conflicting conclusions may result from the different contents of minerals in the mixtures. Further research is still needed to sort out the effects of soil constituents (e.g., minerals and OC) on the properties and 
sorption capacity of biochars.

Consequently, the primary objective of this study is to investigate physicochemical properties (e.g., C\%, surface or bulk polarity, SA) of soil mixtures containing various biochars. At the same time, the effects of these biochars on sorption capacity of biochar-amended agriculture soil was also evaluated. The pesticides selected for this study were: atrazine and isoproturon, toxic herbicides that have been widely used around the world to control annual grasses and broadleaf weeds in agriculture; imidacloprid, an insecticide applied to control sucking and soil insects including plant hoppers, aphids, termites and other harmful pest species (Lewis et al., 2015). All these compounds along with their metabolites are frequently detected in surface and ground waters as a result of their high leachability, which leads to a potential long-term threat to the environment because of their persistence in the environment (Barbash et al., 2001; Garrido-Herrera et al., 2006). It is hypothesized that the effect of soil minerals on the SA of biochar is dependent on the application rate of biochar, i.e., the mineral contents in the mixtures. Also, due to the mixing of biochar with soil, the intrinsic sorption capacity of biochar would be different in mixtures with different biochar contents.

\section{Materials and methods}

2.1. Soil, pure biochars and biochar-amended soils

The soil used in the study was collected from the $0-20 \mathrm{~cm}$ horizon of an agricultural 
field in Tongzhou District, Beijing, China. Its $\mathrm{pH}$ in water was 8.6. It was a silt loam soil with $8.7 \%$ sand, $76.1 \%$ silt, and $15.2 \%$ clay. The soil minerals were mainly composed of illite and montmorillonite. Also, various kinds of herbicide and pesticide are widely used in this area (Sun et al., 2013). Thus, it is of interest to investigate the impacts of biochar addition on sorption of the chemicals by soil. The soil was air-dried at room temperature and the plant residues were removed before use.

The pure biochars were produced from rice, wheat straw and swine manure biomass; the details on biochar production were described elsewhere (Sun et al., 2013a). Briefly, all these air-dried feedstocks were ground to pass through a $1.5 \mathrm{~mm}$ mesh, and then charred for $1 \mathrm{~h}$ in a closed container under oxygen-limited conditions in a muffle furnace. Next, the HTTs were raised to target temperature, that is, 300, 450, and $600{ }^{\circ} \mathrm{C}$, at a ramp rate of $10{ }^{\circ} \mathrm{C} / \mathrm{min}$. The obtained biochars were washed with $0.1 \mathrm{M} \mathrm{HCl}$ followed by ionized water flushing till neutral $\mathrm{pH}$ (Azargohar and Dalai, 2006), then were oven dried at $105{ }^{\circ} \mathrm{C}$. According to the feedstock source (rice and wheat straw, swine manure), the pure biochars produced at $300{ }^{\circ} \mathrm{C}, 450{ }^{\circ} \mathrm{C}$ and $600{ }^{\circ} \mathrm{C}$ were referred as R300, R450, R600; W300, W450, W600; S300, S450, S600. The biochar amended soils used in the experiment were prepared by mixing the soil and pure biochars at different ratios. The percentages of each biochar material in the soil were $1 \%, 5 \%, 10 \%$ and $20 \%(\mathrm{w} / \mathrm{w})$. To guarantee uniformity, both the soil and the biochar samples were passed through a $0.25 \mathrm{~mm}$ sieve prior to use in the study. The soil and biochar were mixed by hand first. Then, they were thoroughly mixed on a 
rotary shaker for $7 \mathrm{~d}$ as sorbents for sorption experiment. The biochar-soil mixtures were named as $1 \%$ SR $300,5 \%$ SR300, 10\%SR300, 20\%SR300; 1\%SR450, 5\%SR450, 10\%SR450, 20\%SR450; 1\%SR600, 5\%SR600, 10\%SR600, 20\%SR600; 1\%SW300, 5\%SW300, 10\%SW300, 20\%SW300; 1\%SW450, 5\%SW450, 10\%SW450, 20\%SW450; 1\%SW600, 5\%SW600, 10\%SW600, 20\%SW600; 1\%SS300, 5\%SS300, 10\%SS300, 20\%SS300; 1\%SS450, 5\%SS450, 10\%SS450, 20\%SS450; 1\%SS600, 5\%SS600, 10\%SS600, 20\%SS600. The first capital "S" represents soil, and the second capitals stand for pure biochars (i.e., R-rice, W-wheat and S-swine).

\subsection{Sorbates}

Imidacloprid (1-[(6-chloro-3-pyridinyl) methyl]- $N$-nitro-2 imidazolidinimine, purity > 98\%) and isoproturon (3-(4-isopropylphenyl)-1, 1-dimethylurea, purity > 99\%) were obtained from Dr. Ehrenstorfer (Augsburg, Germany). Atrazine (2-Chloro-4-ethylamino-6-isopropylamino-1, 3, 5-triazine) was purchased from Tokyo Chemical Industry Co., Ltd. (Japan) with a reported purity $>97 \%$. The selected properties of these pesticides are given in Table S2.

\subsection{Characterization of sorbents}

The bulk $\mathrm{C}, \mathrm{H}, \mathrm{O}$ and $\mathrm{N}$ content of the pure biochars, soil only and biochar-amended soils were measured by Elementar Vario ELIII elemental analyzer through complete combustion. Ash content was determined by heating samples at $750{ }^{\circ} \mathrm{C}$ for $4 \mathrm{~h}$. The solid-state cross-polarization magic-angle-spinning ${ }^{13} \mathrm{C}$ nuclear 
magnetic resonance $\left({ }^{13} \mathrm{C} N M R\right)$ spectra data of pure biochars were obtained with Bruker Avance 300 NMR spectrometer (Karlsruhe, Germany). The detailed NMR running parameters and chemical shift assignments were reported elsewhere (Sun et al., 2013a). The ${ }^{13} \mathrm{C}$ NMR results of pure biochars were provided in Supplementary Material (Table S3). The surface structure and morphological features of the selected samples were investigated by scanning electron microscope (SEM) imaging analysis (Hitachi S4800, Japan) with an acceleration energy of $10 \mathrm{kV}$; the surface chemical characteristics at the same surface locations was also recorded using energy dispersive X-ray spectrometer (EDS, EMAX250, equipped with a X-max ${ }^{N}$ silicon drift X-ray detector), which provides semi-quantitative analysis of element distribution and composition with a sampling depth of 1-2 $\mu \mathrm{m}$. For SEM/EDS analysis, samples were glued onto copper tapes which attached to SEM device. Then the samples were coated with an about 8-10 nm Pt-layer to avoid charging of the organic structures under observation. Acceleration energy of $10 \mathrm{kV}$ was selected to obtain SEM. X-ray photoelectron spectroscopy (XPS) with a Kratos Axis Ultra electron spectrometer using monochromatic $\mathrm{Al} \mathrm{K \alpha}$ source operated at $225 \mathrm{~W}$ was also carried out to probe specific surface elemental composition of the top surface layer $(3-5 \mathrm{~nm})$ of sorbents. The surface area and microporosity of all sorbents was determined by $\mathrm{N}_{2}(77 \mathrm{~K}$, $\mathrm{N}_{2}$-SA) and $\mathrm{CO}_{2}\left(273 \mathrm{~K}, \mathrm{CO}_{2}\right.$-SA) adsorption on an Autosorb-1 gas analyzer (Quantachrome Instruments Corp., Boynton Beach, FL, USA) after outgassing at $105{ }^{\circ} \mathrm{C}$ for $8 \mathrm{~h}$. 


\subsection{Sorption experiments}

Sorption experiments for imidacloprid were conducted for all application rates of biochar-amended soils, whereas for atrazine and isoproturon, only sorption to selected biochar-soil mixtures were conducted. The sorption of atrazine and isoproturon was investigated to test if the sorption enhancement effect of biochar on soil holds for a wider range of organic chemicals. The sorbates solution was stored in methanol and then diluted by the background solution containing $0.01 \mathrm{~mol} / \mathrm{L} \mathrm{CaCl}_{2}$ and $200 \mathrm{mg} / \mathrm{L}$ $\mathrm{NaN}_{3}$ to simulate a constant ionic strength in environmental water and inhibit microbial activity, respectively. It should be noted that methanol concentrations (methanol / water, $\mathrm{v} / \mathrm{v}$ ) were controlled at less than $0.1 \%$ to avoid cosolvent effects. The initial concentrations $(0.2-100 \mathrm{mg} / \mathrm{L}$ for imidacloprid, $0.2-60 \mathrm{mg} / \mathrm{L}$ for isoproturon, and $0.075-25 \mathrm{mg} / \mathrm{L}$ for atrazine) were chosen to cover the range between detection limit and aqueous solubility. Batch equilibration techniques were conducted to obtain the sorption isotherms of the sorbates in 8-mL glass vials at $23 \pm$ $1{ }^{\circ} \mathrm{C}$. In order to achieve $20 \%$ - $80 \%$ uptake of initial concentration at equilibrium, appropriate amounts of sorbents (3000 mg for soil, 4 - $35 \mathrm{mg}$ for pristine biochar, and $20-1000 \mathrm{mg}$ for the mixture) were added to the vials. In all of the samples, each concentration point was done in duplicate. Blank controls (i.e., without sorbents) were run concurrently to investigate sorption to the walls of the glassware. All the vials were placed in a box to prevent photolysis. On the basis of preliminary tests, the vials were shaken on a rotary shaker at room temperature for $2 \mathrm{~d}$ to reach the apparent sorption 
equilibrium. After equilibrium, all the vials were placed upright for $24 \mathrm{~h}$ to separate solution from solids. Then, about $2 \mathrm{~mL}$ supernatant was taken out and analyzed directly by high-performance liquid chromatography (HPLC, Dionex, Ultimate 3000) equipped with a reversed-phase C18 column $(250 \mathrm{~mm} \times 4.6 \mathrm{~mm} \times 5 \mu \mathrm{m}$, Supelco, Bellefonte, PA) and a UV detector operated at a wavelength of $269 \mathrm{~nm}$ for imidacloprid, $240 \mathrm{~nm}$ for isoproturon, and $222 \mathrm{~nm}$ for atrazine. The mobile phase for imidacloprid was acetonitrile/water (65/35, volume ratio), for isoproturon was acetonitrile/water (75/25, volume ratio), and for atrazine was methanol/water (70/30, volume ratio), respectively. The flow rate of all three kinds of sorbates was $1 \mathrm{~mL} / \mathrm{min}$, and the column temperature was set at $40{ }^{\circ} \mathrm{C}$. All samples, along with blanks, were conducted in duplicate. As the sorption by the vials was insignificant shown from the analysis of blank experiments, the uptake of sorbate by the sorbents was calculated by mass balance assuming no other losses. In addition, the $\mathrm{pH}$ of the solutions was detected before and after the sorption experiments, with range of 6.3-7.2.

\subsection{Data analysis}

The sorption data were fitted with Freundlich sorption isotherm equation (logarithmic form):

$$
\begin{gathered}
\log q_{\mathrm{e}}=\log K_{\mathrm{F}}+n \log C_{\mathrm{e}} \\
K_{\mathrm{d}}=q_{\mathrm{e}} / C_{\mathrm{e}} \\
K_{\mathrm{oc}}=K_{\mathrm{d}} / f_{\mathrm{oc}}
\end{gathered}
$$


where $q_{\mathrm{e}}$ is the solid-phase concentration $(\mu \mathrm{g} / \mathrm{g}), C_{\mathrm{e}}$ is the solution phase concentration $(\mu \mathrm{g} / \mathrm{L}), K_{\mathrm{F}}$ is the sorption affinity parameter $\left((\mu \mathrm{g} / \mathrm{g}) /(\mu \mathrm{g} / \mathrm{L})^{\mathrm{n}}\right), n$ is the nonlinear coefficient, $K_{\mathrm{d}}$ is the sorption distribution coefficient, and $K_{\mathrm{oc}}$ is the OC-normalized $K_{\mathrm{d}}$. The $K_{\mathrm{d}}$ and $\log K_{\mathrm{oc}}$ values $\left(C_{\mathrm{e}}=0.01,0.1\right.$ and $1 S_{\mathrm{w}}$, water solubility of solutes) of pure biochars, soil alone and biochar-amended soils were calculated according to the above equations. Statistical analyses, such as Pearson correlation coefficients ( $p$ and $r$ values) among properties of sorbents and the sorption coefficients of sorbates by all sorbents were achieved using SPSS 18.0 software (SPSS Inc). The fitting was processed with Sigmaplot 10.0.

\section{Results and discussion}

\subsection{Characterization of biochar-amended soil samples}

The properties of soil, pure biochars and biochar-soil mixtures are shown in Table S1. The soil used in the study was mainly composed of ash, only containing $0.3 \%$ OC, and the $\mathrm{O}$ content of organic matter $(\mathrm{OM})$ within the soil was lower than the detection limits. The $\mathrm{CO}_{2}$-SA of soil was $10.85 \mathrm{~m}^{2} / \mathrm{g}$, while the $\mathrm{N}_{2}$-SA of soil was $6.468 \mathrm{~m}^{2} / \mathrm{g}$.

The OC and $\mathrm{N}$ contents of the soil-biochar mixtures correlated positively with biochar dose (Fig. S1), suggesting that biochar and soil were well mixed and homogeneous. The enhancement of soil OC and $\mathrm{N}$ contents with addition of biochar can improve soil nutrition and quality (Cernansky, 2015; Marris, 2006). Also, the surface C determined by XPS generally showed an increase with increasing biochar 
addition (Table S1). The surface $\mathrm{C}$ of mixed samples was strikingly higher than their corresponding bulk C (Fig. S2), indicating that OM of biochar-amended soils probably covers the minerals after blending. The bulk $(\mathrm{O}+\mathrm{N}) / \mathrm{C}$ ratio and the surface $(\mathrm{O}+\mathrm{N}) / \mathrm{C}$ ratio were calculated. It should be noted that the bulk elements was measured with elemental analyzer, and contained only those elements that can be decomposed by thermal treatment, mainly from the organic fraction. While, the surface elements measured with XPS contained those from both OM and inorganic minerals. The bulk $(\mathrm{O}+\mathrm{N}) / \mathrm{C}$ ratio, surface $\mathrm{O}$ content, and surface $(\mathrm{O}+\mathrm{N}) / \mathrm{C}$ ratio (except for the $5 \%$ level) of biochar-amended soils roughly decreased with biochar application (Fig. 1), which was probably due to the relative lower polarity of biochar compared with soil. The increased hydrophobicity may facilitate the sorption of HOCs (Chefetz and Xing, 2009). Moreover, it is interesting to note that the surface $(\mathrm{O}+\mathrm{N}) / \mathrm{C}$ ratio and surface $\mathrm{O}$ content at certain application rates even exceeded those of soil and the corresponding pure biochars, for example, 1\%SR300, 1\%SW300 and 1\%SS300 (Fig. 1). The higher surface $(\mathrm{O}+\mathrm{N}) / \mathrm{C}$ ratio and surface $\mathrm{O}$ content for a few soil/biochar samples might result from the occurrence of slight oxidation and/or further surface exposure of polar groups. The latter may be caused by minerals within biochar-soil mixtures, as derived from the significantly positive relationship between surface $(\mathrm{O}+\mathrm{N}) / \mathrm{C}$ ratio and ash content (with $r=0.75, p<0.01)$ as well as surface Si content $(r=0.89, p<0.01)$ (Fig. S3a and b). It can be deduced that minerals in biochar used in this study, such as illite and montmorillonite, are likely to influence the spatial distribution and benefit the exposure 
of polar functional groups of the mixtures (Sun et al., 2013a).

Moreover, the SEM and EDS were used to investigate the morphological and chemical properties of the sorbents. Analogous regions of wheat straw biochars derived at three HTTs (i.e., $300,450,600{ }^{\circ} \mathrm{C}$ ) were selected to investigate the effect of HTT on surface morphology of biochars (Fig. S4). It was worthwhile to note that the number of micropores in the similar region of three biochar surfaces increased with HTTs (Fig. S4). In addition, there are very large differences in mineral and OM content or composition on the surfaces of soil and biochar particles, which were manifested at a micrometer level (Fig. S5). It can be observed from the SEM and EDS spectrograms (Fig. S5) that the surfaces of soils mostly consisted of abundant minerals, and a few of OM granules were associated with mineral surfaces, whereas the surfaces of W450-biochar particles comprised mainly OC, both of which were in accordance with surface composition by XPS.

The $\mathrm{CO}_{2}$-SA and microporosity of pure biochars $\left(89.60-499.20 \mathrm{~m}^{2} / \mathrm{g}\right)$ were much higher than that of soil only $\left(10.85 \mathrm{~m}^{2} / \mathrm{g}\right)$ (Table $\left.\mathrm{S} 1\right)$. The $\mathrm{CO}_{2}-\mathrm{SA}$ and microporosity of biochar-amended soils showed a striking increase with biochar addition rate (Fig. S6 and Table S1), implying potentially enhanced sorptive sites available for HOCs. The $\mathrm{N}_{2}$-SA of 300 and $450{ }^{\circ} \mathrm{C}$ biochar-amended soils had no conspicuous change with biochar addition rate, whereas the $\mathrm{N}_{2}$-SA values of $600{ }^{\circ} \mathrm{C}$ biochar-amended soils showed an obvious growing trend with biochar dose (Table S1). This possibly arises from relatively larger $\mathrm{N}_{2}$-SA of $600{ }^{\circ} \mathrm{C}$ biochars relative to the corresponding 
low-temperature ones, whose $\mathrm{N}_{2}$-SA was similar to that of soil. It was noteworthy that the $\mathrm{CO}_{2}-\mathrm{SA}(r=0.87, p<0.01)$ and $\mathrm{N}_{2}-\mathrm{SA}(r=0.44, p<0.01)$ of biochar-soil mixtures was significantly and positively correlated with bulk OC (Fig. S3c and d), manifesting that $\mathrm{OC}$ makes a dramatic contribution to enhancement of $\mathrm{CO}_{2}-\mathrm{SA}$ and $\mathrm{N}_{2}-\mathrm{SA}$. Nevertheless, this discovery was inconsistent with the previous studies about NOM, in which the $\mathrm{N}_{2}$-SA increased with increasing ash content and decreasing OC content (Ran et al., 2013). The difference between the present and the previous study could be attributed to that the OM used in the studies were from different sources. It has been proved that the porosity of $\mathrm{NOM}$ and biochars were derived from different components (Han et al., 2014). Furthermore, the $\mathrm{CO}_{2}$-SA of biochar-soil mixtures was much larger than their respective $\mathrm{N}_{2}-\mathrm{SA}$ (Table $\mathrm{S} 1$ ), indicating that $\mathrm{N}_{2}$ and $\mathrm{CO}_{2}$ probe different regions of $\mathrm{OM}$ matrices. $\mathrm{N}_{2}$ might primarily present the external surface of $\mathrm{OM}$ and mineral particles, while $\mathrm{CO}_{2}$ could also detect interior pores of $\mathrm{OM}$ simultaneously (Pignatello et al., 2006; Sun et al., 2013b).

3.2 Comparison of the predicted and observed physicochemical properties of biochar-amended soil

The predicted and experiment results of elemental composition and surface area were also compared. Based on mass balance and assuming no cross-effect between soil and biochar (Chen and Yuan, 2011), the predicted values of $\mathrm{C} \%, \mathrm{H} \%, \mathrm{~N} \%, \mathrm{~N}_{2}-\mathrm{SA}$, and $\mathrm{CO}_{2}-\mathrm{SA}$ of the mixtures were obtained as follows: 


$$
E_{\text {mixture }}=f_{\text {soil }} E_{\text {soil }}+f_{\text {biochar }} E_{\text {biochar }}
$$

where, $E_{\text {mixture }}$ is the predicted value of $\mathrm{C} \%, \mathrm{H} \%, \mathrm{~N} \%, \mathrm{~N}_{2}-\mathrm{SA}$, or $\mathrm{CO}_{2}-\mathrm{SA}$ of the mixtures; $E_{\text {soil }}$ and $E_{\text {biochar }}$ are the elemental values of $\mathrm{C} \%, \mathrm{H} \%, \mathrm{~N} \%, \mathrm{~N}_{2}-\mathrm{SA}$, or $\mathrm{CO}_{2}$-SA in soil and pure biochar, respectively; $f_{\text {soil }}$ and $f_{\text {biochar }}$ are the soil and biochar contents in the mixture, respectively. Because the $\mathrm{O} \%$ of the soil was under detection limit, the predicted value of $\mathrm{O} \%$ of the mixtures was not calculated.

It is worth noting that the predicted $\mathrm{C} \%, \mathrm{H} \%$, and $\mathrm{N} \%$ in biochar-amended soils (Fig. S1) were not uniformly consistent with the determined ones. Moreover, the predicted value was roughly higher than the corresponding determined value (Fig. S1 and Table 1). The most distinct attenuation effect was generally detected at the biochar-soil ratio of $10 \%$ and $20 \%$ (Fig. S1), suggesting the strongest interaction between soil and biochar. The attenuation effect could be due to the cross-effect between the soil components and the biochar and/or the natural oxidation of the mixtures (Liang et al., 2008; Teixidó et al., 2013). Minerals were reported to be able to remove the authigenic OM away from the biochar's surface (Li et al., 2015).

For soils amended with biochars produced at 300 and $450{ }^{\circ} \mathrm{C}$ excluding W450, the predicted $\mathrm{N}_{2}$-SA values in biochar-amended samples were slightly smaller than the determined ones (Table 1). This indicates the possible interaction between the individual components, biochar and soil, which could exhibit pore-expanding effect. Different from $\mathrm{N}_{2}-\mathrm{SA}$, the predicted $\mathrm{CO}_{2}-\mathrm{SA}$ values of the mixtures at the biochar content of $10 \%$ and $20 \%$ were obviously higher than the experimental values, except 
for soils amended with wheat biochars (Fig. S6). There are probably two reasons for the reduction of $\mathrm{CO}_{2}$-SA of mixtures with $10 \%$ and $20 \%$ biochar. 1) The loss of OC in the mixtures with $10 \%$ and $20 \%$ biochar (Fig. S1 and Table 1) might lead to the decrease of $\mathrm{CO}_{2}-\mathrm{SA}$, as $\mathrm{OC}$ was the major contributor to the $\mathrm{CO}_{2}-\mathrm{SA}$ of biochar. 2) Pores of the individual components may be blocked, which will be detailed later.

Attributing all attenuation in $\mathrm{CO}_{2}-\mathrm{SA}$ of the mixture to the biochar component, the intrinsic $\mathrm{CO}_{2}$-SA of the biochar $\left(\mathrm{SA}_{\text {biochar }}\right)$ in the mixture could be calculated by subtracting out the contribution of the soil:

$$
\mathrm{SA}_{\text {int }}=\mathrm{SA}_{\text {mix }} / f_{\text {biochar }}-f_{\text {soil }} \mathrm{SA}_{\text {soil }} / f_{\text {biochar }}
$$

The results of the $\mathrm{SA}_{\text {int }}$ were shown in Table $\mathrm{S} 1$. The $\mathrm{SA}_{\text {int }}$ was enhanced by 1.11-2.51 times after applying biochar into soil at rate of $1 \%$, excluding soil amended with $1 \%$ SW600. The SA-expanding effect could also be confirmed by SEM analysis as shown in Fig. S4. 1\%SW300 contained more micropores than SW300 in the similar region. The SA-expanding effect was also observed in other studies (Heitkötter and Marschner, 2015; Li et al., 2015; Trigo et al., 2014) and was attributed to the elimination of the organic film from the biochar surface by soil minerals. During the cooling process, after thermal treatment to produce biochar, some micropores should be blocked by noncarbonized OM, the byproducts of biomass pyrolysis at relatively low temperature (Keiluweit et al., 2012). The solvent-extractable polycyclic aromatic hydrocarbons (PAHs) of the tested biochar have been detected in our previous study, with PAH content of $610.0-4734.0 \mu \mathrm{g} / \mathrm{kg}$ 
(Qiu et al., 2015). Removing the solvent-extractable matter from the biochar, the obviously enhanced SA was observed (Nguyen et al., 2007). Thus, it is reasonable to propose that the pore surface of biochars is coated by some OM removable by soil minerals. In addition, the content of noncarbonized $\mathrm{OM}$ in biochar decreased with increasing HTT (Keiluweit et al., 2010), which might attenuate the SA-expanding effect. Consistently, the enlargement of $\mathrm{CO}_{2}$-SA generally decreased with increasing HTT (Table S1). In contrast, for soils amended with $10 \%$ and $20 \%$ biochars, the blend with soil attenuated the $\mathrm{CO}_{2}$-SA of biochar by as much as 1.34 times (10\%SW600) (Table S1). In other words, at most roughly $25 \%$ pores of biochar were either lost with the loss of $\mathrm{C}$ or unavailable for $\mathrm{CO}_{2}$ sorption after blending with soil. Taking all the results into account, it can be concluded that the influence of soil minerals on the SA of biochar is dependent on the application rate of biochar.

\subsection{Sorption of solutes to soil and pure biochars}

Sorption isotherms of imidacloprid, isoproturon, and atrazine by the soil alone and the pure biochars are shown in Fig. S7 and S8, respectively, and the Freundlich parameters are listed in Tables S4, S5 and S6, respectively. The sorption isotherms for soil and pure biochars were all highly nonlinear $(n<0.74)$, reflecting the dominance of adsorption mechanisms. The sorption isotherms of pure biochars are more nonlinear than that of soil alone, which can be attributed to their much higher $\mathrm{CO}_{2}-\mathrm{SA}$ compared to soil (Table S1). Consistently, the $n$ values for imidacloprid and 
isoproturon of pure biochars exhibited downward trends with increasing $\mathrm{N}_{2}-\mathrm{SA}$, $\mathrm{CO}_{2}$-SA, and pore volume (Table S7), implying that pore-filling could be a major mechanism regulating sorption nonlinearity of these polar chemicals. Significantly negative relationships between the $n$ values of imidacloprid as well as isoproturon and the aromaticity of pure biochar (Table S7) support that aromatic moieties should be the predominant components responsible for nonlinear sorption process, consistent with previous studies (Chefetz and Xing, 2009; Han et al., 2014; Xing and Pignatello, 1997).

Biochar exhibited much greater $K_{\mathrm{d}}\left(C_{\mathrm{e}}=0.01 S_{\mathrm{w}}\right)$ values, referred as $K_{\mathrm{d}}(0.01)$, than soil for the tested solutes (Table S4, S5 and S6). Therefore, pure biochars are expected to enhance the sorption of the solutes when added to soils. The $\log K_{\mathrm{oc}}$ of isoproturon for soil was also lower than that for pure biochars (Fig. 2). However, for imidacloprid and atrazine, soil had higher $\log K_{\mathrm{oc}}$ values than biochars produced at 300 ${ }^{\circ} \mathrm{C}$, and $\operatorname{lower} \log K_{\mathrm{oc}}$ values than biochars produced at 450 and $600{ }^{\circ} \mathrm{C}$ (Fig. 2 and Table S6). Thus, biochars produced at high HTTs are more powerful sorption medium for imidacloprid and atrazine in comparison with soil, consistent with other studies (Chen et al., 2008; Wang et al., 2016).

The $K_{\mathrm{d}}(0.01)$ of pure biochars ranged along the order: swine $<$ rice $\leqslant$ wheat (except for the sorption of imidacloprid by S600) (Table S4, S5 and S6). Furthermore, the $\log K_{\mathrm{oc}}$ of all solutes by pure biochars increased with increasing HTT (Fig. 2 and Table S6). Sorption $\left(\log K_{\mathrm{oc}}\right)$ by pure biochars generally follows the order: isoproturon $\approx$ atrazine > imidacloprid, the same as the order in n-octanol-water partition 
coefficient $\left(\log K_{\text {ow }}\right)$ : isoproturon $(2.50) \approx$ atrazine $(2.70)>$ imidacloprid $(0.57)$ (Table S2). This result underscores the importance of hydrophobic effects. In addition, the $\log K_{\mathrm{oc}}$ of imidacloprid and isoproturon calculated at $C_{\mathrm{e}}=0.01 S_{\mathrm{w}}$, named as $\log K_{\mathrm{oc}}$ (0.01), correlated negatively with $\mathrm{O} \%$, polarity $((\mathrm{O}+\mathrm{N}) / \mathrm{C})$, and polar $\mathrm{C}$ content $($ Table S7). The trends also imply that hydrophobic partitioning play a significant role in sorption of imidacloprid and isoproturon.

Moreover, as given in Table S7, for imidacloprid, the $K_{\mathrm{d}}$ increased with increasing $\mathrm{CO}_{2}$-SA and decreasing $\mathrm{H} / \mathrm{C}$ ratio. The $\log K_{\mathrm{oc}}$ of imidacloprid further correlated positively with aryl C content and negatively with aliphatic C content (Table S7). For the pristine biochars, the $\log K_{\mathrm{oc}}(0.01)$ of isoproturon correlated well with $\mathrm{CO}_{2}$-SA and aryl $\mathrm{C}$ content, and inversely with $\mathrm{H} / \mathrm{C}$ ratio and alkyl $\mathrm{C}$ content, but poorly with $\mathrm{N}_{2}$ surface area $\left(\mathrm{N}_{2}-\mathrm{SA}\right)$. Taken together, the trends indicate that biochar affinity for imidacloprid and isoproturon increased with the degree of carbonization and micropore development in the biochar, consistent with other studies (Han et al., 2014; Jin et al., 2014; Teixidó et al., 2013).

3.4 Enhanced sorption of solutes to soils amended with biochar

Sorption of imidacloprid, isoproturon and atrazine to biochar-amended soils was investigated. The sorption isotherms are presented in Fig. S7 and S8, and the regression parameters are listed in Tables S4, S5 and S6. Sorption in the mixtures increased as expected with biochar dose (Fig. 3). The sorption enhancement effect of 
biochar on soil was quantified by dividing the $K_{\mathrm{d}}$ of the mixtures $\left(K_{\mathrm{d}}\right.$, mixture $)$ by the $K_{\mathrm{d}}$ of the soil alone $\left(K_{\mathrm{d} \text {, soil }}\right)$, which was expressed as $K_{\mathrm{d} \text {, mixture }} / K_{\mathrm{d} \text {, soil }}$ (Table $\mathrm{S} 4, \mathrm{~S} 5$ and S6). For instance, with the addition of 1\%SR600, 5\%SR600, 10\%SR600, and $20 \%$ SR600, the $K_{\mathrm{d}}(0.01)$ of imidacloprid was enhanced by $8.28,62.20,110.81$, and 220.43 times, respectively, in comparison with soil. This also provides sufficient evidences for the high efficiency of biochar addition in reducing the pore water concentration of imidacloprid in soil. It was noted that the $K_{\mathrm{d}}$ values of imidacloproid and isoproturon by biochar-soil mixtures were positively correlated with the bulk OC content, $\mathrm{CO}_{2}-\mathrm{SA}$, and $\mathrm{N}_{2}$-SA, and negatively with polarity (Fig. 4). Thus, the enhancement effect could be result from the increased bulk $\mathrm{C}$ content, the enlarged SA, and the decreased hydrophobicity.

Here, it should be noted that the $\log K_{\mathrm{oc}}(0.01)$ of imidacloprid by $1 \% \mathrm{SR} 300$, $5 \%$ SR300, $10 \%$ SR300, $1 \%$ SW300, and 5\%SW300 was higher than that of the individual sorbents (Fig. 2). Also, the $20 \%$ SW300 gave greater sorption capacity $\left(\log K_{\mathrm{oc}}\right)$ of atrazine than soil alone and pure biochar at $C_{\mathrm{e}} / S_{\mathrm{w}}=0.01-1$ (Table S6). The $\log K_{\mathrm{oc}}$ of the mixture is expected to be within the range of $\log K_{\mathrm{oc}}$ values for the individual sorbents. We propose that these nonintuitive behaviors can be explained, in part, by the interactions between biochars and abundant soil minerals or other soil components, which may provide additional sorption sites for atrazine and imidacloprid. In addition, above the biochar content of $5 \%$, the $\log K_{\mathrm{oc}}(0.01)$ for imidacloprid and isoproturon almost remained stable. This implies that biochar 
dominates the sorption of imidacloprid and isoproturon at content of $5 \%$ and above.

Various biochars imposed different effects on soil sorption enhancement. For a given application rate of biochar, the enhancement of sorption capacity for the mixtures generally followed the same order as OC content and sorption capacity of the pure biochars: swine $<$ wheat $\approx$ rice, and were inverse to the ash content (Table S1, S4, S5, and S6). In addition, at a given biochar application rate, sorption enhancement of soil with the biochar addition generally increased with the pyrolytic temperature (Table S4, S5, and S6). For instance, the swine biochar produced at $300{ }^{\circ} \mathrm{C}$ gave the lowest enhancement for imidacloprid sorption, but still up to 1.72-16.06 folds for various application rates (Table S4).

3.5 Comparison of the predicted and experimental sorption capacity of imidacloprid by the biochar-amended soil

The effects of soil constituents (e.g., minerals and OC) on the sorption capacity of biochars can be quantified by comparing the observed sorption capacity with the predicted sorption capacity. The latter was calculated by assuming total sorption as the sum of two independent, noninteracting domains, soil and biochar. Because of the detailed sorption data, the sorption of imidacloprid was taken as an example. The predicted total sorption of biochar-amended soil was calculated as follows,

$$
q_{\text {predict }}=f_{\text {soil }} K_{\text {soil }} C_{\mathrm{e}}^{m}+f_{\text {biochar }} K_{\text {biochar }} C_{\mathrm{e}}^{n}
$$

Thus, the predicted $K_{\text {mix, pre }}$ can be defined as, 


$$
K_{\text {mix, pre }}=f_{\text {soil }} K_{\mathrm{d}, \text { soil }}+f_{\text {biochar }} K_{\mathrm{d} \text {, biochar }}
$$

where, $K_{\text {soil }}$ and $K_{\text {biochar }}$ are the sorption affinity parameters of soil and biochar, respectively; $m$ and $n$ are the Freundlich exponents of soil and biochar sorption, respectively; $K_{\text {mix, pre }}$ is the predicted sorption distribution coefficient of the mixtures,

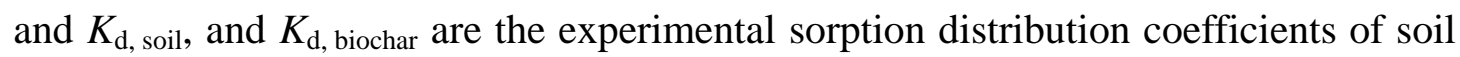
and pure biochar, respectively.

The $K_{\text {mix, pre }}$ was plotted as a function of application rate $(0$ and $100 \%$ for soil and biochar, respectively) in Fig. 3. Noteworthy from Fig. 3 are the following results. First, for biochars at the content of $10 \%$ and $20 \%$ excluding SR300 and SW300, the actual $K_{\text {mix,exp }}$ values were slightly smaller than the predicted data. The attenuation effect might be caused by two reasons. 1) The loss of OC during the preparation of the mixtures (Fig. S1). As mentioned above, the $K_{\mathrm{d}}(0.01)$ of imidacloprid by the mixtures correlated positively with the OC content (Fig. 4). Thereby, the obviously reduced OC content (Fig. S1) of the mixtures with biochar content of $10 \%$ and $20 \%$ compared to the predicted values would inevitably weaken their sorption affinity for HOCs. 2) The $\mathrm{OM}$ and native sorbates in soil may compete for or block biochar surface adsorption sites (Cornelissen and Gustafsson, 2005; Cornelissen et al., 2005), thus reducing available sorption sites for imidacloprid. Consistently, the predicted $\mathrm{CO}_{2}$-SA values of the mixtures with $10 \%$ and $20 \%$ biochar were obviously higher than the experimental values (Fig. S6).

Second, for the sorption of imidacloprid by soils amended with SR300 and 
SW300, the observed $K_{\text {mix, exp }}$ is higher than the predicted $K_{\text {mix, pre }}$ (Fig. 3), despite the fact that the C\% of SR300 and SW300 were also reduced (Fig. S1). As mentioned above, pore-filling is the dominant mechanism for sorption of imidacloprid. Also, the $K_{\mathrm{d}}$ of imidacloprid by the mixtures was positively correlated to the $\mathrm{N}_{2}-\mathrm{SA}$ values (Fig. 4c). Therefore, the enlarged $\mathrm{N}_{2}-\mathrm{SA}$ values of the soils amended with SR300 and SW300 could compensate for the decrease of C\%, enhancing the $K_{\text {biochar }}$ of imidacloprid (Table S4). We can conclude from these results that models assuming no cross-effect between soil and biochar could overpredict (for relatively high application rate) or underestimate (for biochar produced at low HTT) the sorption capacity of imidacloprid.

Like $\mathrm{SA}_{\text {int }}$, attributing all interaction effects between soil and biochar in the mixture to the biochar component permits calculation of the intrinsic $K_{\text {biochar }}$ for the affected biochar after subtracting out the contribution of the soil:

$$
K_{\text {int, biochar }}=K_{\mathrm{d}, \text { mix }} / f_{\text {biochar }}-f_{\text {soil }} K_{\text {d, soil }} / f_{\text {biochar }}
$$

It is of interest to find 1.3-5.6 times enhancement in $K_{\text {int, biochar }}$ of imidacloprid by soil amended with SR300 and SW300, depending on the biochar, solute concentration, and biochar concentration (Table 2). For other sorption systems, compared to the raw biochar, the presence of soil suppresses the intrinsic $K_{\text {int, biochar }}$ by as much as 3.8 times for imidacloprid (Table 2).

\section{Conclusions}


The results of this study indicate that it is possible to considerably reduce the pore water concentration of imidacloprid, isoproturon, and atrazine in soils by amending the soils with biochar at levels of a few percent. The sorption capacity of the mixtures increased with increasing biochar application rate and pyrolytic temperature. At a given biochar application rate, biochar derived from swine waste exhibited lower enhancement of sorption capacity than plant residue-derived biochars. Enhancement effect correlates with SA and C\%. Thus, biochars produced from plant materials at high temperature would be useful for contaminant immobilization purposes. For soils amended with $10 \%$ and $20 \%$ biochars, the $\mathrm{C} \%, \mathrm{H} \%, \mathrm{~N} \%$, and $\mathrm{CO}_{2}-\mathrm{SA}$ values were lower than the predicted values. Excluding SR300 and SW300, for mixtures with biochar content of $10 \%$ and $20 \%$, the experimental sorption distribution coefficients of imidacloprid were slightly smaller than the predicted data. In contrast, for SR300 and SW300, the intrinsic sorption capacities of biochar were enhanced by 1.3-5.6 times. Thus, to improve prediction of the sorption capacity of the biochar-soil mixtures, the cross-effect between the soil and the biochar should be considered. In soil and sediment, biochar surfaces are potentially altered over time by abiotic or biotic oxidation and the deposition of NOM, ions, and minerals (Teixidó et al., 2013). However, in this study, the biochar-soil mixtures were used without weathering treatment. The weathering effect on sorption capacity of the biochar-soil mixture warrants further study. 


\section{Acknowledgements}

This research was supported by National Natural Science Foundation of China (41273106, 41473087, and 41522303), National Science Foundation for Innovative Research Group (51121003), and Beijing Higher Education Young Elite Teacher Project (YETP0273).

\section{Appendix A. Supplementary data}

Supplementary data related to this article can be found at http://www.ees.elsevier.com/envpol.

\section{References}

Azargohar, R., Dalai, A., 2006. Biochar as a precursor of activated carbon. Appl. Biochem. Biotechnol. $131,762-773$.

Barbash, J.E., Thelin, G.P., Kolpin, D.W., Gilliom, R.J., 2001. Major herbicides in ground water. J. Environ. Qual. 30, 831-845.

Cernansky, R., 2015. State-of-the-art soil. Nature 517, 258-260.

Chefetz, B., Xing, B., 2009. Relative role of aliphatic and aromatic moieties as sorption domains for organic compounds: a Review. Environ. Sci. Technol. 43, 1680-1688.

Chen, B., Yuan, M., 2011. Enhanced sorption of polycyclic aromatic hydrocarbons by soil amended with biochar. J. Soils Sediments 11, 62-71.

Chen, B., Zhou, D., Zhu, L., 2008. Transitional adsorption and partition of nonpolar and polar aromatic contaminants by biochars of pine needles with different pyrolytic temperatures. Environ. Sci. Technol. 42, 5137-5143. 
Cornelissen, G., Gustafsson, Ö., 2005. Importance of unburned coal carbon, black carbon, and amorphous organic carbon to phenanthrene sorption in sediments. Environ. Sci. Technol. 39, 764-769.

Cornelissen, G., Gustafsson, Ö., Bucheli, T.D., Jonker, M.T., Koelmans, A.A., van Noort, P.C., 2005. Extensive sorption of organic compounds to black carbon, coal, and kerogen in sediments and soils: mechanisms and consequences for distribution, bioaccumulation, and biodegradation. Environ. Sci. Technol. 39, 6881-6895.

Garcia-Jaramillo, M., Cox, L., Knicker, H.E., Cornejo, J., Spokas, K.A., Hermosín, M.C., 2015. Characterization and selection of biochar for an efficient retention of tricyclazole in a flooded alluvial paddy soil. J. Hazard. Mater. 286, 581-588.

Garrido-Herrera, F., González-Pradas, E., Fernández-Pérez, M., 2006. Controlled release of isoproturon, imidacloprid, and cyromazine from alginate-bentonite-activated carbon formulations. J. Agric. Food Chem. 54, 10053-10060.

Han, L., Sun, K., Jin, J., Wei, X., Xia, X., Wu, F., Gao, B., Xing, B., 2014. Role of structure and microporosity in phenanthrene sorption by natural and engineered organic matter. Environ. Sci. Technol. 48, 11227-11234.

Heitkötter, J., Marschner, B., 2015. Interactive effects of biochar ageing in soils related to feedstock, pyrolysis temperature, and historic charcoal production. Geoderma 245, 56-64.

Jin, J., Sun, K., Wu, F., Gao, B., Wang, Z., Kang, M., Bai, Y., Zhao, Y., Liu, X., Xing, B., 2014. Single-solute and bi-solute sorption of phenanthrene and dibutyl phthalate by plant-and manure-derived biochars. Sci. Total Environ. 473, 308-316.

Jones, D.L., Edwards-Jones, G., Murphy, D.V., 2011. Biochar mediated alterations in herbicide breakdown and leaching in soil. Soil Biol. Biochem. 43, 804-813.

Keiluweit, M., Kleber, M., Sparrow, M.A., Simoneit, B.R., Prahl, F.G., 2012. Solvent-extractable polycyclic aromatic hydrocarbons in biochar: influence of pyrolysis temperature and feedstock. Environ. Sci. Technol. 46, 9333-9341.

Keiluweit, M., Nico, P.S., Johnson, M.G., Kleber, M., 2010. Dynamic molecular structure of plant biomass-derived black carbon (biochar). Environ. Sci. Technol. 44, 1247-1253. 
Lehmann, J., 2007. A handful of carbon. Nature 447, 143-144.

Lehmann, J., Joseph, S., 2009. Biochar for Environmental Management: Science and Technology. Earthscan: London.

Lewis, K.A., Green, A., Tzilivakis, J. and Warner, D., 2015. The Pesticide Properties DataBase (PPDB) developed by the Agriculture \& Environment Research Unit (AERU), University of Hertfordshire, 2006-2015.

Li, J., Li, S., Dong, H., Yang, S., Li, Y., Zhong, J., 2015. Role of alumina and montmorillonite in changing the sorption of herbicides to biochars. J. Agric. Food Chem. 63, 5740-5746.

Liang, B., Lehmann, J., Solomon, D., Sohi, S., Thies, J.E., Skjemstad, J.O., Luizão, F.J., Engelhard, M.H., Neves, E.G., Wirick, S., 2008. Stability of biomass-derived black carbon in soils. Geochim. Cosmochim. Acta 72, 6069-6078.

Marris, E., 2006. Putting the carbon back: black is the new green. Nature 442, 624-626.

Nguyen, T.H., Cho, H.-H., Poster, D.L., Ball, W.P., 2007. Evidence for a pore-filling mechanism in the adsorption of aromatic hydrocarbons to a natural wood char. Environ. Sci. Technol. 41, 1212-1217.

Pignatello, J.J., Kwon, S., Lu, Y., 2006. Effect of natural organic substances on the surface and adsorptive properties of environmental black carbon (char): attenuation of surface activity by humic and fulvic acids. Environ. Sci. Technol. 40, 7757-7763.

Qiu, M., Sun, K., Jin, J., Han, L., Sun, H., Zhao, Y., Xia, X., Wu, F., Xing, B., 2015. Metal/metalloid elements and polycyclic aromatic hydrocarbon in various biochars: The effect of feedstock, temperature, minerals, and properties. Environ. Pollut. 206, 298-305.

Ran, Y., Yang, Y., Xing, B., Pignatello, J.J., Kwon, S., Su, W., Zhou, L., 2013. Evidence of micropore filling for sorption of nonpolar organic contaminants by condensed organic matter. J. Environ. Qual. 42, 806-814.

Sun, K., Jin, J., Keiluweit, M., Kleber, M., Wang, Z., Pan, Z., Xing, B., 2012. Polar and aliphatic domains regulate sorption of phthalic acid esters (PAEs) to biochars. Bioresour. Technol. 118, 120-127.

Sun, K., Kang, M., Zhang, Z., Jin, J., Wang, Z., Pan, Z., Xu, D., Wu, F., Xing, B., 2013a. Impact of deashing treatment on biochar structural properties and potential sorption mechanisms of 
phenanthrene. Environ. Sci. Technol. 47, 11473-11481.

Sun, K., Ran, Y., Yang, Y., Xing, B., Mao, J., 2013b. Interaction mechanism of benzene and phenanthrene in condensed organic matter: importance of adsorption (nanopore-filling). Geoderma 204-205, 68-74.

Sun, X., Zhou, Q., Ren, W., 2013. Herbicide occurrence in riparian soils and its transporting risk in the Songhua River Basin, China. Agron. Sustain. Dev. 33, 777-785.

Teixidó, M., Hurtado, C., Pignatello, J.J., Beltrán, J.L., Granados, M., Peccia, J., 2013. Predicting contaminant adsorption in black carbon (biochar)-amended soil for the veterinary antimicrobial sulfamethazine. Environ. Sci. Technol. 47, 6197-6205.

Trigo, C., Spokas, K.A., Cox, L., Koskinen, W.C., 2014. Influence of soil biochar aging on sorption of the herbicides MCPA, nicosulfuron, terbuthylazine, indaziflam, and fluoroethyldiaminotriazine. J. Agric. Food Chem. 62, 10855-10860.

Wang, Z., Han, L., Sun, K., Jin, J., Ro, K.S., Libra, J.A., Liu, X., Xing, B., 2016. Sorption of four hydrophobic organic contaminants by biochars derived from maize straw, wood dust and swine manure at different pyrolytic temperatures. Chemosphere 144, 285-291.

Woolf, D., Amonette, J.E., Street-Perrott, F.A., Lehmann, J., Joseph, S., 2010. Sustainable biochar to mitigate global climate change. Nat. Commun. 1, 1-9.

Xing, B., Pignatello, J.J., 1997. Dual-mode sorption of low-polarity compounds in glassy poly (vinyl chloride) and soil organic matter. Environ. Sci. Technol. 31, 792-799.

Yang, Y., Sheng, G., 2003. Enhanced pesticide sorption by soils containing particulate matter from crop residue burns. Environ. Sci. Technol. 37, 3635-3639. 
Table 1

Comparison between the predicted and the measured values of $\mathrm{C} \%, \mathrm{H} \%, \mathrm{~N} \%, \mathrm{~N}_{2}$ surface area $\left(\mathrm{N}_{2^{-}}\right.$ $\mathrm{SA})$, and $\mathrm{CO}_{2}$ surface area $\left(\mathrm{CO}_{2}-\mathrm{SA}\right)$ of biochar-soil mixtures.

\begin{tabular}{|c|c|c|c|c|c|c|c|c|c|c|}
\hline \multirow{2}{*}{ Samples } & \multicolumn{2}{|c|}{$\mathrm{C}(\%)$} & \multicolumn{2}{|c|}{$\mathrm{H}(\%)$} & \multicolumn{2}{|c|}{$\mathrm{N}(\%)$} & \multicolumn{2}{|c|}{$\mathrm{N}_{2}-\mathrm{SA}\left(\mathrm{m}^{2} / \mathrm{g}\right)$} & \multicolumn{2}{|c|}{$\mathrm{CO}_{2}-\mathrm{SA}\left(\mathrm{m}^{2} / \mathrm{g}\right)$} \\
\hline & $\operatorname{pre}^{\mathrm{a}}$ & $\mathrm{mes}^{\mathrm{b}}$ & pre & mes & pre & mes & pre & mes & pre & mes \\
\hline $1 \%$ SR300 & 0.9 & 0.9 & 0.31 & 0.32 & 0.02 & 0.02 & 6.452 & 7.388 & 12.62 & 13.55 \\
\hline $5 \%$ SR300 & 3.1 & 3.0 & 0.45 & 0.48 & 0.05 & 0.04 & 6.386 & 7.353 & 19.73 & 20.52 \\
\hline $10 \%$ SR300 & 5.8 & 5.2 & 0.63 & 0.67 & 0.09 & 0.06 & 6.303 & 6.488 & 28.61 & 24.75 \\
\hline $20 \%$ SR 300 & 11.3 & 9.9 & 0.97 & 0.99 & 0.17 & 0.14 & 6.139 & 5.873 & 46.38 & 39.05 \\
\hline $1 \%$ SR450 & 0.9 & 0.9 & 0.31 & 0.29 & 0.02 & 0.01 & 6.467 & 7.716 & 13.67 & 13.99 \\
\hline $5 \%$ SR450 & 3.2 & 2.9 & 0.43 & 0.40 & 0.05 & 0.04 & 6.465 & 7.515 & 24.98 & 24.95 \\
\hline $10 \%$ SR 450 & 6.1 & 5.4 & 0.58 & 0.53 & 0.09 & 0.08 & 6.463 & 7.795 & 39.10 & 34.31 \\
\hline $20 \%$ SR 450 & 11.8 & 9.8 & 0.89 & 0.78 & 0.17 & 0.15 & 6.458 & 7.619 & 67.36 & 54.31 \\
\hline 1\%SR600 & 0.9 & 1.0 & 0.30 & 0.31 & 0.02 & 0.02 & 7.693 & 8.344 & 14.65 & 15.60 \\
\hline $5 \%$ SR600 & 3.3 & 3.1 & 0.38 & 0.36 & 0.05 & 0.05 & 12.593 & 14.546 & 29.84 & 27.20 \\
\hline $10 \%$ SR600 & 6.2 & 5.6 & 0.49 & 0.41 & 0.09 & 0.07 & 18.718 & 19.620 & 48.82 & 42.51 \\
\hline $20 \%$ SR600 & 12.1 & 10.0 & 0.69 & 0.56 & 0.17 & 0.12 & 30.969 & 30.814 & 86.80 & 73.18 \\
\hline $1 \%$ SW300 & 0.9 & 1.0 & 0.32 & 0.35 & 0.02 & 0.02 & 6.429 & 7.792 & 12.36 & 14.31 \\
\hline $5 \%$ SW300 & 3.5 & 3.4 & 0.49 & 0.55 & 0.04 & 0.03 & 6.274 & 8.441 & 18.42 & 19.90 \\
\hline $10 \%$ SW300 & 6.6 & 5.7 & 0.69 & 0.81 & 0.06 & 0.06 & 6.080 & 7.049 & 25.99 & 23.84 \\
\hline $20 \%$ SW300 & 12.9 & 10.2 & 1.10 & 1.10 & 0.11 & 0.08 & 5.692 & 6.450 & 41.14 & 38.58 \\
\hline $1 \%$ SW450 & 1.0 & 1.0 & 0.32 & 0.30 & 0.01 & 0.02 & 6.433 & 6.173 & 14.24 & 14.79 \\
\hline $5 \%$ SW 450 & 3.8 & 3.6 & 0.48 & 0.49 & 0.03 & 0.04 & 6.295 & 4.454 & 27.79 & 34.37 \\
\hline $10 \%$ SW 450 & 7.3 & 6.5 & 0.68 & 0.57 & 0.06 & 0.05 & 6.122 & 4.404 & 44.73 & 39.13 \\
\hline $20 \%$ SW450 & 14.3 & 12.1 & 1.08 & 0.84 & 0.10 & 0.09 & 5.777 & 4.707 & 78.62 & 65.34 \\
\hline $1 \%$ SW600 & 1.1 & 1.0 & 0.31 & 0.31 & 0.01 & 0.02 & 8.310 & 5.165 & 15.73 & 15.03 \\
\hline $5 \%$ SW600 & 4.2 & 3.8 & 0.42 & 0.38 & 0.03 & 0.03 & 15.677 & 12.597 & 35.27 & 30.21 \\
\hline $10 \%$ SW600 & 8.1 & 7.0 & 0.56 & 0.51 & 0.05 & 0.05 & 24.886 & 18.560 & 59.68 & 47.06 \\
\hline $20 \%$ SW600 & 15.8 & 13.2 & 0.84 & 0.72 & 0.09 & 0.08 & 43.304 & 31.016 & 108.52 & 125.90 \\
\hline $1 \% \mathrm{SS} 300$ & 0.7 & 0.7 & 0.31 & 0.30 & 0.04 & 0.04 & 6.434 & 7.962 & 11.64 & 12.99 \\
\hline $5 \%$ SS300 & 2.1 & 2.0 & 0.45 & 0.41 & 0.17 & 0.13 & 6.298 & 7.611 & 14.79 & 11.69 \\
\hline $10 \% \mathrm{SS} 300$ & 3.9 & 3.5 & 0.61 & 0.55 & 0.33 & 0.24 & 6.129 & 6.873 & 18.72 & 17.60 \\
\hline $20 \%$ SS300 & 7.5 & 5.8 & 0.94 & 0.78 & 0.65 & 0.41 & 5.790 & 5.971 & 26.60 & 24.71 \\
\hline $1 \% \mathrm{SS} 450$ & 0.6 & 0.7 & 0.30 & 0.31 & 0.04 & 0.03 & 6.471 & 8.752 & 12.36 & 13.05 \\
\hline $5 \% \mathrm{SS} 450$ & 2.0 & 2.0 & 0.39 & 0.37 & 0.14 & 0.11 & 6.482 & 7.117 & 18.41 & 16.31 \\
\hline $10 \% \mathrm{SS} 450$ & 3.6 & 3.3 & 0.51 & 0.41 & 0.27 & 0.20 & 6.497 & 6.748 & 25.96 & 22.96 \\
\hline $20 \% S S 450$ & 7.0 & 5.9 & 0.73 & 0.60 & 0.52 & 0.39 & 6.525 & 8.633 & 41.08 & 33.06 \\
\hline $1 \%$ SS600 & 0.7 & 0.7 & 0.30 & 0.31 & 0.03 & 0.03 & 6.751 & 6.135 & 12.80 & 13.44 \\
\hline $5 \%$ SS600 & 2.1 & 2.2 & 0.36 & 0.34 & 0.13 & 0.11 & 7.884 & 8.531 & 20.61 & 20.67 \\
\hline $10 \%$ SS600 & 3.8 & 3.6 & 0.43 & 0.36 & 0.26 & 0.19 & 9.301 & 9.531 & 30.37 & 28.51 \\
\hline $20 \%$ SS600 & 7.4 & 6.3 & 0.58 & 0.50 & 0.50 & 0.34 & 12.133 & 12.895 & 49.90 & 43.01 \\
\hline
\end{tabular}

${ }^{\mathrm{a}}$ The predicted value of the biochar-soil mixture.

$\mathrm{b}$ The measured value of the biochar-soil mixture. 
Table 2

The intrinsic sorption distribution coefficient of imidacloprid for biochar in the biochar-soil mixtures after subtracting out the contribution of the soil.

\begin{tabular}{|c|c|c|c|c|c|c|}
\hline & \multicolumn{3}{|c|}{$K_{\text {int, biochar }}^{\mathrm{a}}$} & \multicolumn{3}{|c|}{$K_{\text {int, biochar }} / K_{\mathrm{d}, \text { biochar }}{ }^{\mathrm{b}}$} \\
\hline & $C_{\mathrm{e}}=0.01 S_{\mathrm{w}}$ & $C_{\mathrm{e}}=0.1 S_{\mathrm{w}}$ & $C_{\mathrm{e}}=1 S_{\mathrm{w}}$ & $C_{\mathrm{e}}=0.01 S_{\mathrm{w}}$ & $C_{\mathrm{e}}=0.1 S_{\mathrm{w}}$ & $C_{\mathrm{e}}=1 S_{\mathrm{w}}$ \\
\hline $1 \%$ SR300 & 171.30 & 54.43 & 14.57 & 2.5 & 3.4 & 3.9 \\
\hline $5 \%$ SR300 & 179.73 & 61.77 & 20.69 & 2.6 & 3.8 & 5.6 \\
\hline $10 \%$ SR300 & 131.47 & 50.78 & 19.44 & 1.9 & 3.2 & 5.2 \\
\hline 20\%SR300 & 91.36 & 36.96 & 14.89 & 1.3 & 2.3 & 4.0 \\
\hline $1 \%$ SR450 & 290.01 & 66.41 & 9.41 & 0.7 & 0.8 & 0.5 \\
\hline $5 \%$ SR450 & 384.37 & 81.62 & 15.87 & 1.0 & 1.0 & 0.9 \\
\hline $10 \%$ SR 450 & 353.04 & 76.62 & 15.94 & 0.9 & 0.9 & 0.9 \\
\hline $20 \%$ SR 450 & 342.47 & 68.64 & 13.42 & 0.9 & 0.8 & 0.7 \\
\hline 1\%SR600 & 502.65 & 96.32 & 10.63 & 0.5 & 0.7 & 0.5 \\
\hline $5 \%$ SR600 & 845.27 & 129.14 & 17.67 & 0.9 & 0.9 & 0.8 \\
\hline $10 \%$ SR600 & 758.42 & 120.62 & 18.23 & 0.8 & 0.8 & 0.8 \\
\hline 20\%SR600 & 757.76 & 117.69 & 17.85 & 0.8 & 0.8 & 0.8 \\
\hline $1 \%$ SW300 & 210.68 & 95.36 & 42.59 & 3.0 & 3.4 & 3.9 \\
\hline $5 \%$ SW300 & 186.45 & 73.29 & 28.49 & 2.6 & 2.6 & 2.6 \\
\hline $10 \%$ SW300 & 100.62 & 50.95 & 25.79 & 1.4 & 1.8 & 2.4 \\
\hline $20 \%$ SW300 & 99.57 & 38.19 & 14.57 & 1.4 & 1.4 & 1.3 \\
\hline $1 \%$ SW450 & 410.80 & 98.10 & 17.65 & 0.9 & 0.9 & 0.7 \\
\hline $5 \%$ SW 450 & 482.72 & 108.11 & 22.83 & 1.1 & 1.0 & 0.9 \\
\hline $10 \%$ SW450 & 428.40 & 94.28 & 20.07 & 1.0 & 0.9 & 0.8 \\
\hline $20 \%$ SW450 & 404.50 & 90.01 & 19.73 & 0.9 & 0.9 & 0.8 \\
\hline 1\%SW600 & 210.31 & 44.97 & 3.69 & 0.4 & 0.5 & 0.3 \\
\hline $5 \%$ SW600 & 442.99 & 71.37 & 9.55 & 0.9 & 0.8 & 0.7 \\
\hline $10 \%$ SW600 & 432.00 & 68.94 & 10.06 & 0.8 & 0.8 & 0.7 \\
\hline $20 \%$ SW600 & 430.12 & 64.99 & 9.38 & 0.8 & 0.8 & 0.7 \\
\hline $1 \% \mathrm{SS} 300$ & 50.42 & 25.73 & 13.01 & 0.8 & 0.9 & 1.1 \\
\hline $5 \%$ SS300 & 62.78 & 26.45 & 10.95 & 0.9 & 0.9 & 0.9 \\
\hline $10 \% \mathrm{SS} 300$ & 61.77 & 25.76 & 10.63 & 0.9 & 0.9 & 0.9 \\
\hline $20 \%$ SS300 & 52.62 & 24.18 & 11.09 & 0.8 & 0.8 & 0.9 \\
\hline $1 \% \mathrm{SS} 450$ & 195.04 & 46.18 & 5.87 & 0.8 & 0.8 & 0.4 \\
\hline $5 \% \mathrm{SS} 450$ & 192.47 & 47.60 & 10.63 & 0.8 & 0.8 & 0.8 \\
\hline $10 \% \mathrm{SS} 450$ & 198.86 & 47.16 & 10.59 & 0.8 & 0.8 & 0.8 \\
\hline $20 \% S S 450$ & 199.65 & 48.90 & 11.72 & 0.8 & 0.8 & 0.8 \\
\hline $1 \%$ SS600 & 279.72 & 64.13 & 8.96 & 0.5 & 0.6 & 0.4 \\
\hline $5 \%$ SS600 & 416.58 & 86.81 & 16.59 & 0.8 & 0.8 & 0.8 \\
\hline $10 \%$ SS600 & 421.66 & 83.48 & 15.76 & 0.8 & 0.8 & 0.7 \\
\hline $20 \%$ SS600 & 412.49 & 83.69 & 16.65 & 0.8 & 0.8 & 0.8 \\
\hline
\end{tabular}

${ }^{\mathrm{a}}$ The intrinsic sorption distribution coefficient for biochar after subtracting out the contribution of the soil from the biochar-soil mixtures.

${ }^{\mathrm{b}}$ The sorption distribution coefficient for pure biochar. 


\section{Figure captions:}

Fig. 1. Change trend of surface $\mathrm{O}$ content (a), bulk polarity $((\mathrm{O}+\mathrm{N}) / \mathrm{C})(\mathrm{b})$, and surface polarity (c) of biochar-soil mixtures with different biochar addition ratio (SR300, SR450, SR600, SW300, SW450, SW600, SS300, SS450, and SS600 represent biochar-soil mixtures; the first capital "S" of each abbreviation denotes soil, and R, W, and S represent rice, wheat and swine-manure biochars, respectively; 300, 450 and 600 represent heat treatment temperature).

Fig. 2. Change trend of the sorption capacity coefficients $\left(K_{\mathrm{d}}\right.$ or $\left.\log K_{\mathrm{oc}}, C_{\mathrm{e}}=0.01 S_{\mathrm{w}}\right)$ of imidacloprid ( $\mathrm{a}$ and $\mathrm{b}$ ) and isoproturon (c and d) by biochar-soil mixtures with increasing biochar addition ratio (SR300, SR450, SR600, SW300, SW450, SW600, SS300, SS450, SS600 represent biochar-soil mixtures, the first capital "S" of each abbreviation denotes soil, R300, R450, R600, W300, W450, W600, S300, S450, S600 represent rice, wheat and swine-manure biochars produced at 300,450 and $600{ }^{\circ} \mathrm{C}$, respectively).

Fig. 3. Comparison of the predicted and the experimental sorption capacity $\left(K_{\mathrm{d}}, C_{\mathrm{e}}=\right.$ $0.01 S_{\mathrm{w}}$ ) of imidacloprid by the biochar-amended soil. (SR300, SR450, SR600, SW300, SW450, SW600, SS300, SS450, SS600 represent biochar-soil mixtures, the first capital "S" of each abbreviation denotes soil, R300, R450, R600, W300, W450, W600, S300, S450, S600 represent rice, wheat and swine-manure biochars produced at 300,450 and $600{ }^{\circ} \mathrm{C}$, respectively). 
Fig. 4. Correlations between the sorption capacity $\left(K_{\mathrm{d}}\right)$ for imidacloprid and isoproturon by biochar-soil mixtures and the $\mathrm{C}$ content ( $\mathrm{a}$ and $\mathrm{b}$ ), surface area (SA) (c and d), and bulk or surface polarity $((\mathrm{O}+\mathrm{N}) / \mathrm{C})(\mathrm{e}$ and f) $(20 \% \mathrm{SW} 300$ represents soil amended with $20 \%$ wheat-derived biochar produced at $300{ }^{\circ} \mathrm{C}$ and $10 \%$ SR600 represents soil amended with $10 \%$ biochar produced from rice straw at $600{ }^{\circ} \mathrm{C}$ ). 

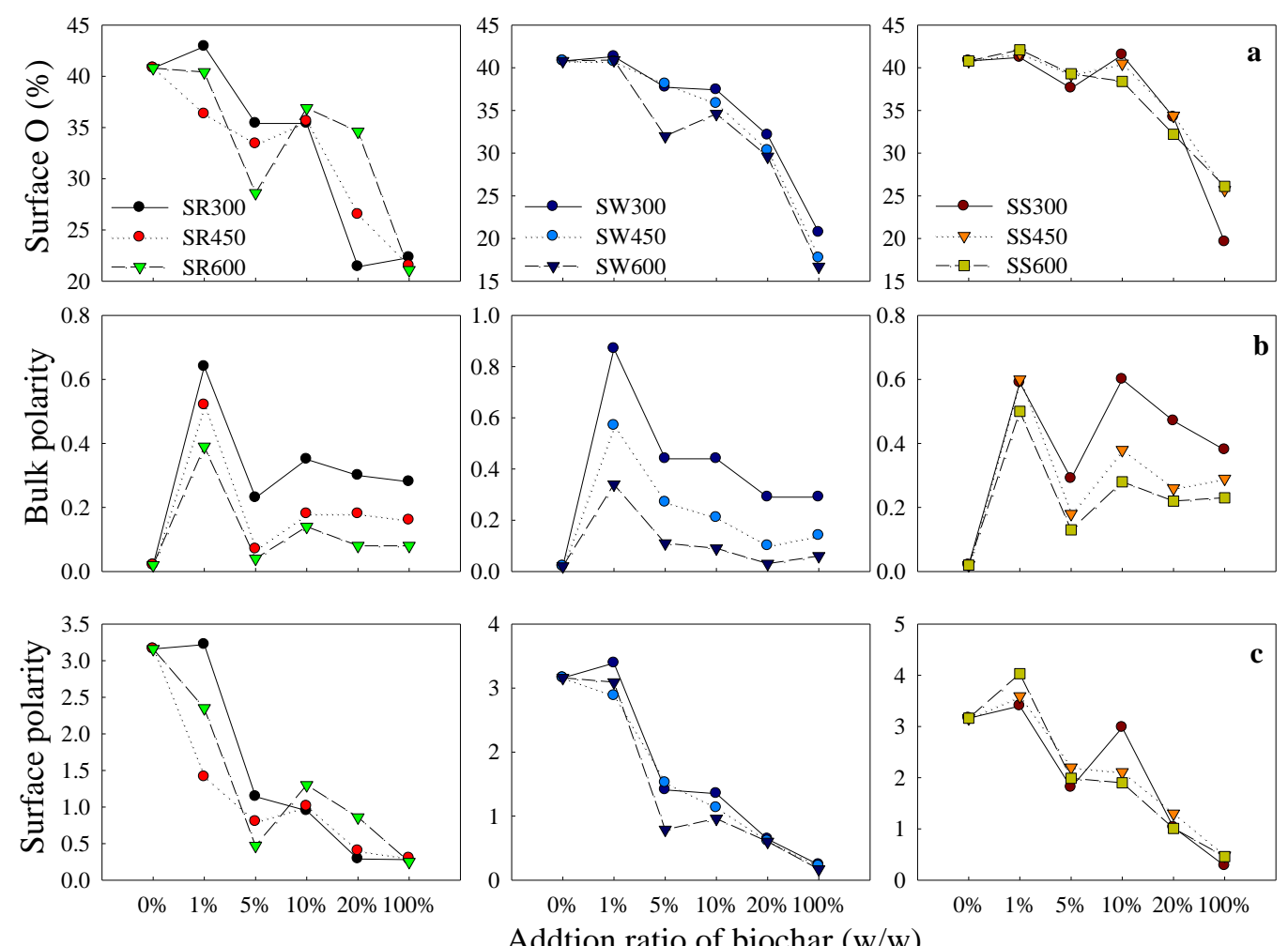

Fig. 1. Change trend of surface $\mathrm{O}$ content (a), bulk polarity $((\mathrm{O}+\mathrm{N}) / \mathrm{C})(\mathrm{b})$, and surface polarity (c) of biochar-soil mixtures with different biochar addition ratio (SR300, SR450, SR600, SW300, SW450, SW600, SS300, SS450, and SS600 represent biochar-soil mixtures; the first capital "S" of each abbreviation denotes soil, and $\mathrm{R}, \mathrm{W}$, and S represent rice, wheat and swine-manure biochars, respectively; 300, 450 and 600 represent heat treatment temperature). 


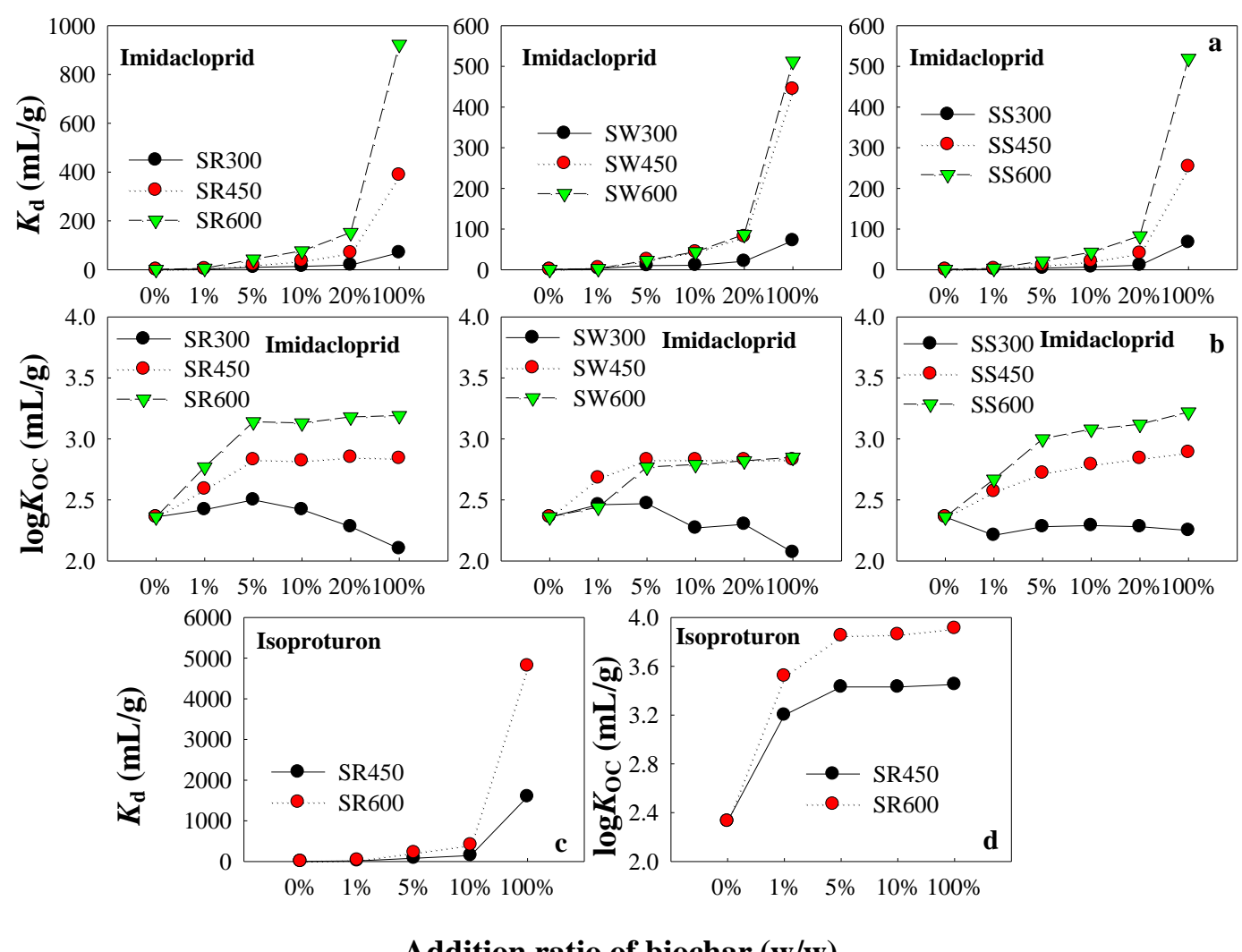

Addition ratio of biochar (w/w)

Fig. 2. Change trend of the sorption capacity coefficients $\left(K_{\mathrm{d}}\right.$ or $\left.\log K_{\mathrm{oc}}, C_{\mathrm{e}}=0.01 S_{\mathrm{w}}\right)$ of imidacloprid ( $\mathrm{a}$ and $\mathrm{b}$ ) and isoproturon (c and d) by biochar-soil mixtures with increasing biochar addition ratio (SR300, SR450, SR600, SW300, SW450, SW600, SS300, SS450, SS600 represent biochar-soil mixtures, the first capital "S" of each abbreviation denotes soil, R300, R450, R600, W300, W450, W600, S300, S450, S600 represent rice, wheat and swine-manure biochars produced at 300,450 and $600{ }^{\circ} \mathrm{C}$, respectively). 

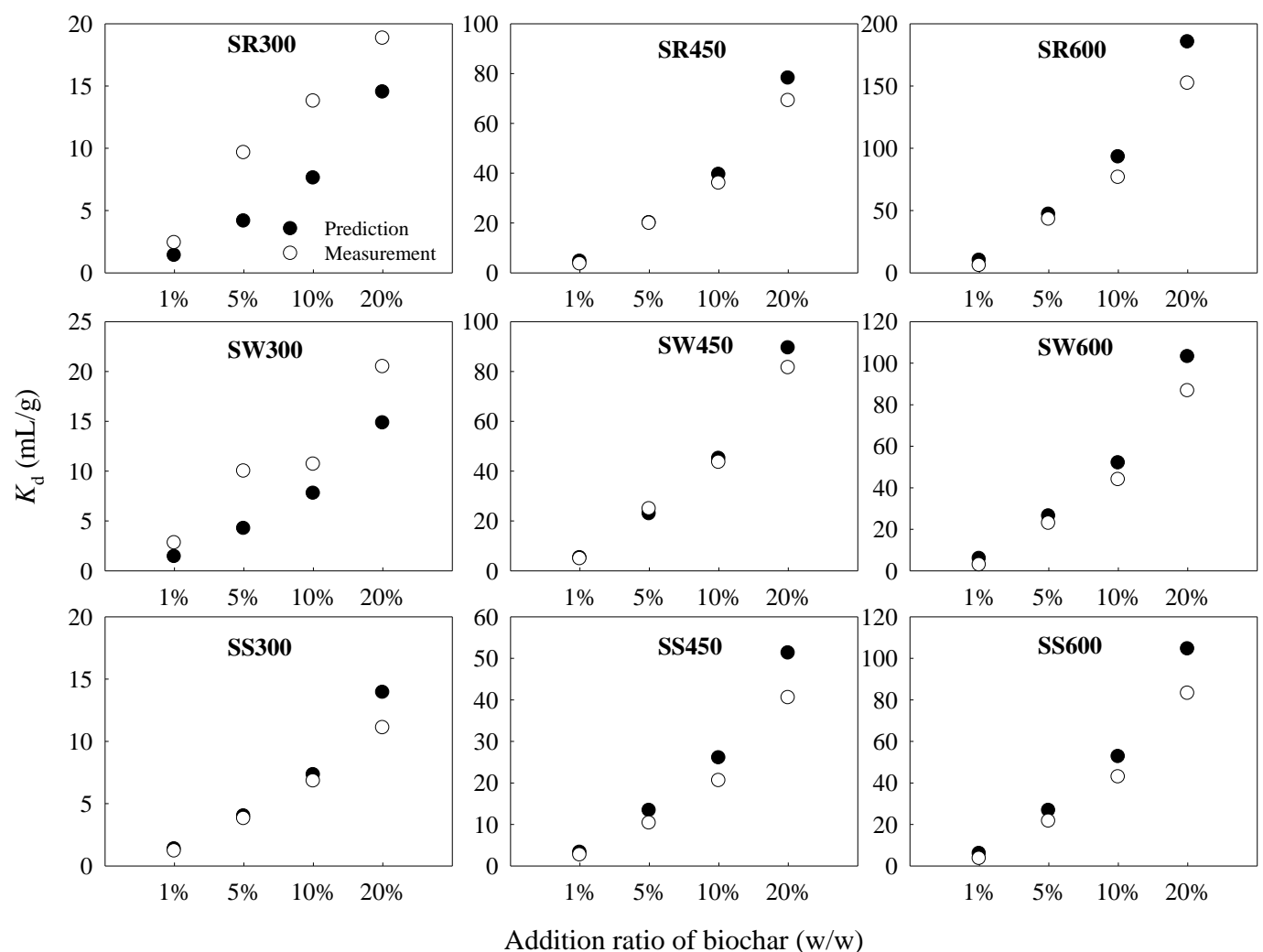

Fig. 3. Comparison of the predicted and the experimental sorption capacity $\left(K_{\mathrm{d}}, C_{\mathrm{e}}=\right.$ $0.01 S_{\mathrm{w}}$ ) of imidacloprid by the biochar-amended soil. (SR300, SR450, SR600, SW300, SW450, SW600, SS300, SS450, SS600 represent biochar-soil mixtures, the first capital "S" of each abbreviation denotes soil, R300, R450, R600, W300, W450, W600, S300, S450, S600 represent rice, wheat and swine-manure biochars produced at 300,450 and $600{ }^{\circ} \mathrm{C}$, respectively). 

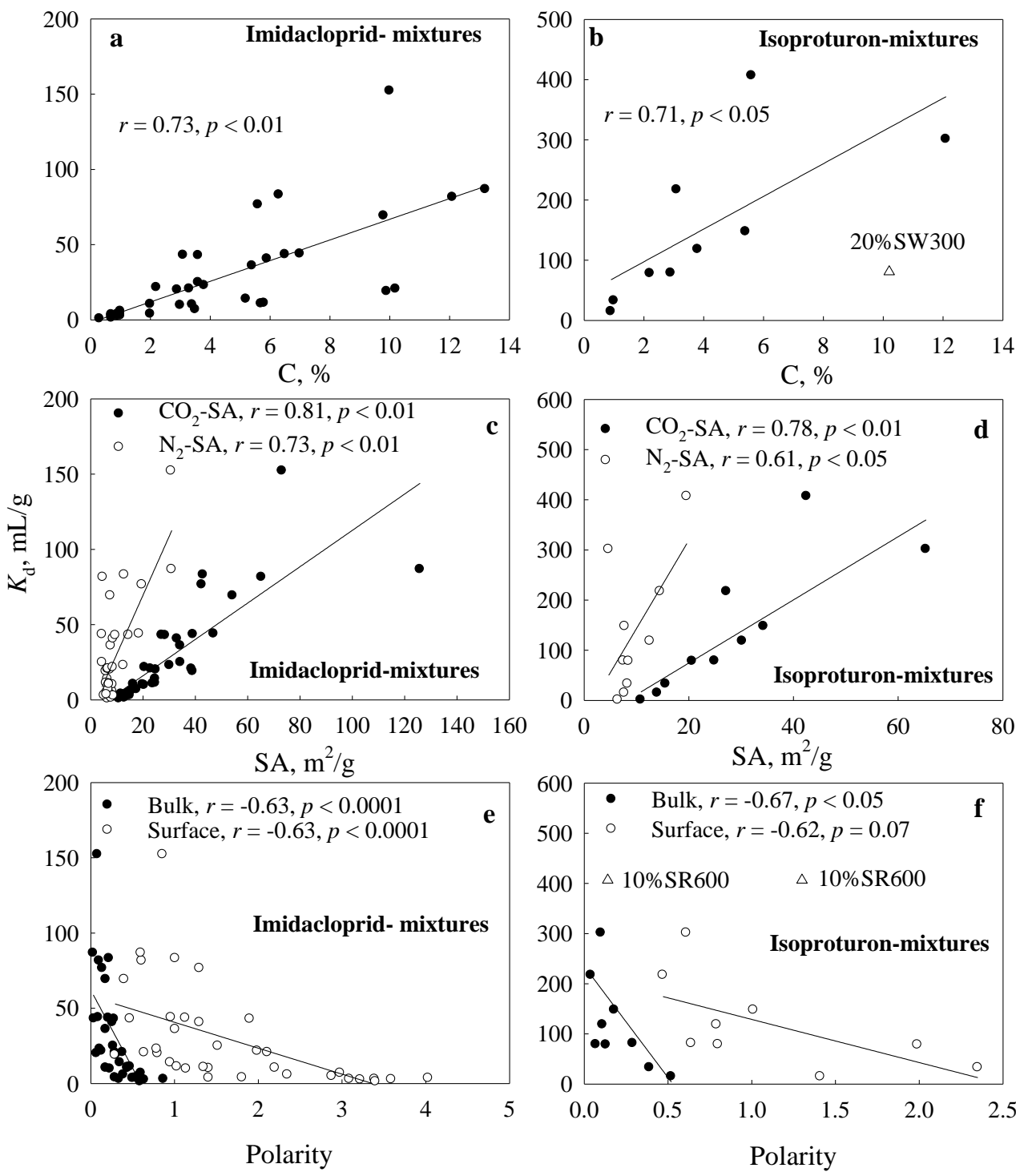

Fig. 4. Correlations between the sorption capacity $\left(K_{\mathrm{d}}\right)$ for imidacloprid and isoproturon by biochar-soil mixtures and the $\mathrm{C}$ content ( $\mathrm{a}$ and $\mathrm{b}$ ), surface area (SA) (c and d), and bulk or surface polarity $((\mathrm{O}+\mathrm{N}) / \mathrm{C})(\mathrm{e}$ and f) $(20 \% \mathrm{SW} 300$ represents soil amended with $20 \%$ wheat-derived biochar produced at $300{ }^{\circ} \mathrm{C}$ and $10 \%$ SR600 represents soil amended with $10 \%$ biochar produced from rice straw at $600{ }^{\circ} \mathrm{C}$ ). 


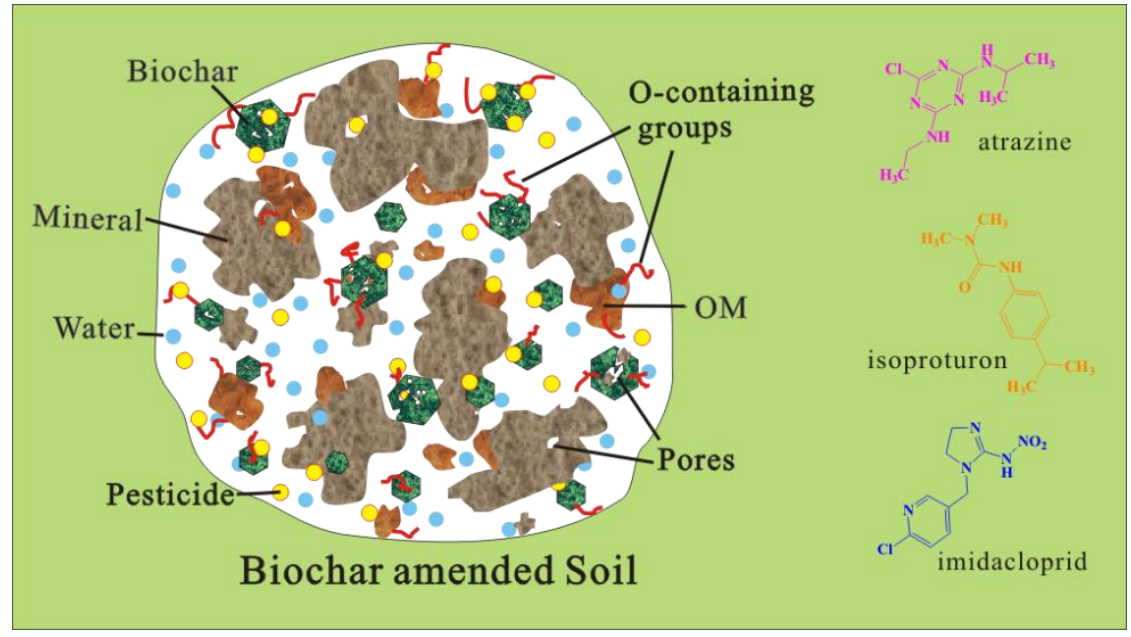

For Table of Contents Only 